\title{
DISABILITY BURDEN OF DIABETES MELLITUS AND ITS COMPLICATIONS
}

\author{
MD. ZIAUL ISLAM
}

\begin{abstract}
This specific analytical cross-sectional study was conducted at the Out Patient Department (OPD) of BIRDEM hospital to estimate and compare disability burden of Diabetes Mellitus (DM) and its complications during the period of January-June 2003. Data was collected by face-to-face interview with a semi-structured questionnaire and a checklist. To estimate disability burden, Years lived with Disability (YLD) was calculated. Out of total 154 patients, $53 \%$ were female while $47 \%$ were male and their mean age was 47.02 ( \pm 8.42$)$ years. Around $48 \%$ patients claimed the onset age of 40-49 years. Average monthly family income of the patients was TK.16,488.27 6042.40 and $27 \%$ of them were illiterate. Out of all, $72 \%$ patients had diabetes with complications while the rest $28 \%$ had diabetes without complications. With regard to disability burden, total 473.43 YLDs was shared by the patients of which only 20.46\% YLD was shared by diabetes itself while major part of YLD (79.54\%) was shared by its complications and the discrepancy was statistically significant (' $t$ ' $\left.{ }_{(152)}=11.34, p<0.01\right)$. It was revealed that the highest YLD was incurred by DM with cardiovascular diseases (37.56\%) followed by DM with retinopathy (19.82\%) and DM with nephropathy (12.98\%). More YLD (52.65\%) was shared by the patients with poor compliance with therapy while $34.27 \%$ and $13.08 \%$ YLD were incurred by the patients with moderate and good compliance with therapy respectively. Older patients shared more YLD than the younger patients and the disparity was statistically significant (' $t$ ' ${ }_{(152)}=9.53, p<0.01$ ). More YLD was shared by the patients with long duration of the disease than the patients with short duration and this divergence was statistically significant (' $t_{(152)}=8.71, p<0.01$ ). The study outcome will recommend for reduction of burden of DM by averting its major complications.
\end{abstract}

Key Words: YLD, DM and Complications

\section{Introduction}

Non-communicable diseases has emerged as a challenge for financing the health system globally. ${ }^{1}$ Diabetes mellitus is a recognized major chronic public health problem throughout the world and WHO has targeted major strategies for prevention \& control of the disease. ${ }^{2}$ It is observed that worldwide prevalence of DM may increase to $5.4 \%$ by the year 2025 and major part of this increase will occur in developing countries. South East Asia Region ranks fourth by prevalence of DM with a $20 \%$ contribution to the world total, which will rise to $27 \%$ by $2025 .^{3-5}$ Diabetes mellitus is now recognized as a major public health problem in Bangladesh. It is estimated that the number of diabetics is 2.5 million and is expected to grow dramatically in the country. ${ }^{6}$ Prevalence DM in a suburban population of Bangladesh in 1995 was estimated $4.1 \%$ (men $4.13 \%$ \& women $3.90 \%$ ). ${ }^{7}$ Another study in 1997 among the rural and urban population of Bangladesh revealed a combined prevalence of DM as $5.2 \%$ (5.5\% men, $4,8 \%$ women) of which rural $3.8 \%$ and urban $7.8 \% .{ }^{8}$ A recent study in rural population of Bangladesh estimated overall prevalence of diabetes as $4.3 \%(5.2 \%$ men \& $3.2 \%$ women). ${ }^{9}$ The overall estimated prevalence of diabetes in Bangladeshi population is $5.6 \%$ and more than $96 \%$ of which are reported as type $2 \mathrm{DM} .{ }^{10,11}$ The trend of increase of DM will certainly alarm the health system of the country, which will attract the health policymakers and health professionals at different level. ${ }^{12-}$ ${ }^{14}$ The World development report focused that diabetes mellitus accounts for $0.8 \%$ YLD of which $1.9 \%$ in developed and $0.7 \%$ in developing regions. ${ }^{15,16} \mathrm{DM}$ causes different organic or systemic complications, which produces extra disability and economic burden to the patients and society. ${ }^{17,18}$ Evidences suggest that both the incidence and prevalence of DM are increasing in Bangladesh. The study aims to estimate disability

Correspondence : Dr. Md. Ziaul Islam, Assistant Professor, Department of Community Medicine, National Institute of Preventive and Social Medicine (NIPSOM), Mohakhali, Dhaka 1212. 
burden of DM and its complications in terms of YLD, which will enable both health care providers and consumers to reduce burden of DM by averting its complications through well management of this chronic disease.

\section{Materials and Methods:}

Disability burden of DM was estimated in terms of Years Lived with Disability (YLD) following the methodology used by WHO in estimation of "Global Burden of Disease". Duration of the disease, age weight, disability weight and time preference was considered in this regard.

Study Design: Cross-sectional type of Analytical study.

Study Period: January to June 2003.

Place of the Study: Out-Patient Department (OPD) of BIRDEM hospital.

Sample Size: The sample size was 154 , which was taken conveniently considering the time and other resource constraints.

Sampling Technique: Systematic random sampling technique was used for data collection and every third patient was interviewed.

Data Collection Tools: A semi-structured questionnaire was used to collect data from the patients and a Checklist was used to collect information from patients' reference book.

Data collection techniques: Face to face interview $\&$ reviewing patients' reference book.
Data Processing and Quality Control: Data was checked for any inconsistency and irrelevancy. Data processing considered categorizing, coding, summarizing and entry of data.

Data Analysis: Data was analyzed by computer using SPSS software (Version 15.0).

\section{Result:}

Out of 154 patients, majority (53.2\%) was female while $46.8 \%$ were male, $36 \%$ were in the age group of $40-49$ years and their mean age of $47.02( \pm \mathrm{SD} 8.42)$ years. A sensible part (26.6\%) was illiterate and their average monthly family income was TK. 16,488.27 ( \pm SD6042.40). By occupation, $45.5 \%$ were housewives, $24.0 \%$ were service holders and $18.2 \%$ were businessmen with. Majority of the patients (72\%) had complicated diabetes and the rest $28 \%$ had uncomplicated diabetes. Complications were more in female (56\%) than their counterpart male (44\%) and it was predominant (36.94\%) among productive age group (40-59 years) than other age groups, which was statistically significant $\left(\mathrm{c}^{2}{ }_{(3)}=41.9, \mathrm{p}<0.001\right)$. Nature of DM was categorized in to 'only DM' (28.0\%), 'DM with single complication' (68.18\%) and 'DM with multiple complications' (3.90\%). Majority of the patients $(68 \%)$ had single \& only $4 \%$ patients had multiple complications. Multiple complications were more among old patients than other age groups with statistical significance $(\mathrm{F}=26.96, \mathrm{p}<0.01)$. Major complications included cardiovascular disease (31.81\%), retinopathy (13.81\%) while $9.74 \%$ and $5.84 \%$ was osteoarthritis and nephropathy respectively (Table-I).

Table-I

Distribution of the patients by complications of DM and YLD

\begin{tabular}{lcc}
\hline Type of complications & Frequency (\%) & YLDs (\%) \\
\hline Cardiovascular disease (CVD) & $49(31.81)$ & $177.85(37.56 \%)$ \\
Retinopathy & $20(13.81)$ & $93.83(19.82)$ \\
Nephropathy & $09(5.84)$ & $61.47(12.98)$ \\
Neuropathy & $07(4.55)$ & $20.00(4.22)$ \\
Ulcer/Gangrene & $04(2.60)$ & $4.22(0.89)$ \\
Osteoarthritis & $15(0.74)$ & $40.17(8.48)$ \\
Skin disease & $01(0.65)$ & $0.90(0.19)$ \\
Both CVD \& Retinopathy & $03(1.95)$ & $18.88(3.99)$ \\
Both Retinopathy \& Skin disease & $01(0.65)$ & $7.75(1.65)$ \\
Both CVD \& Nephropathy & $01(0.65)$ & $10.34(2.18)$ \\
Both CVD \& Skin disease & $01(0.65)$ & $7.18(1.53)$ \\
Uncomplicated DM & $43(27.92)$ & $30.83(6.51)$ \\
\hline Total & $154(100)$ & $473.43(100)$ \\
\hline
\end{tabular}


Regarding disability burden, total 473.43 YLD was shared by the DM patients \& more YLD (38.27\%) was incurred by middle age group (40-49 years) and it was higher (49.0\%) among the middle-income group (TK.5,000-14,999). Mean YLD was more among graduate patients (3.67) than of illiterate patients (3.39) and it was shared more by complicated DM patients (3.98 \pm SD1.86) than by uncomplicated patients $(0.75 \pm \mathrm{SD} 0.12)$ and the difference was statistically significant (' $\mathrm{t}$ ' ${ }_{(152)}=11.34, \mathrm{p}<0.01$ ) (Table-II). Highest YLD was incurred by cardiovascular diseases (37.56\%) while $19.82 \%$ and $12.98 \%$ YLD was shared by retinopathy and nephropathy respectively (Table-I). With regard to therapy, majority of the patients $(50.6 \%)$ were under oral hypoglycemic agent (OHA) followed by $28.6 \%$ were taking Insulin, $11.7 \%$ were on diet control \& daily walking while the rest $9.09 \%$ were treating by both OHA and Insulin. Majority of the patients $(48.05 \%)$ had poor compliance with therapy while $33.12 \%$ had moderate compliance and only $18.83 \%$ had good compliance with therapy. More YLD (52.65\%) was shared by the patients with poor compliance while $34.27 \%$ and $13.08 \%$ YLD was shared by the patients with moderate and good compliance with therapy respectively and the discrepancy was statistically significant $(\mathrm{F}=27.92, \mathrm{p}<0.01)$ (Table-III). It was also emerged that 'DM with multiple complications' incurred more mean YLD (7.36 \pm 2.15$)$ while 'DM with single complication' shared $3.81 \pm 1.66$ and 'DM without complication' shared only $0.75 \pm 0.23$ mean YLD and this disparity was statistically significant $(\mathrm{F}=96.92, \mathrm{p}<0.01)($ Table-IV).

Table-II

Distribution of YLDs by Complications of DM

\begin{tabular}{|c|c|c|c|c|c|}
\hline \multirow[t]{2}{*}{ Type of DM } & \multirow[t]{2}{*}{ Frequency } & \multirow[t]{2}{*}{ Mean YLD $( \pm \mathrm{SD})$} & \multicolumn{3}{|c|}{ ' $t$ ' test } \\
\hline & & & tvalue & $\mathrm{df}$ & $\mathrm{p}$ value \\
\hline Uncomplicated DM & 43 & $0.75( \pm 0.12)$ & 11.34 & 152 & 0.001 \\
\hline Complicated DM & 111 & $3.98( \pm 1.86)$ & & & \\
\hline Total & 154 & $3.07( \pm 2.16)$ & & & \\
\hline
\end{tabular}

Table-III

Distribution of YLDS by patient's compliance with therapy

\begin{tabular}{|c|c|c|c|c|c|}
\hline \multirow{2}{*}{ Patient's Compliance } & \multirow[t]{2}{*}{ Frequency (\%) } & \multirow[t]{2}{*}{ YLD (\%) } & \multirow[t]{2}{*}{ Mean YLD } & \multicolumn{2}{|c|}{ ANOVA } \\
\hline & & & & Fvalue & $\mathrm{p}$ \\
\hline Good compliance & $29(18.83)$ & $61.94(13.08)$ & 2.14 & 27.92 & 0.001 \\
\hline Moderate compliance & $51(33.12)$ & $162.26(34.27)$ & 3.18 & & \\
\hline Poor compliance & $74(48.05)$ & $249.23(52.65)$ & 3.37 & & \\
\hline Total & $154(100)$ & $473.43(100.0)$ & 3.07 & & \\
\hline
\end{tabular}

Table-IV

Distribution of YLD by nature of Diabetes Mellitus

\begin{tabular}{|c|c|c|c|c|c|}
\hline Nature of DM & & & Mean YLD & & $\pm \mathrm{SD}$ \\
\hline Only DM & & & 0.75 & & 0.23 \\
\hline DM with single complication & & & 3.81 & & 1.66 \\
\hline DM with multiple complications & & & 7.36 & & 2.15 \\
\hline Total & & & 3.07 & & 2.16 \\
\hline Source & $\mathrm{df}$ & Sum of square & Mean square & F value & Pvalue \\
\hline Between Groups & 2 & 399.82 & 199.91 & 96.92 & 0.001 \\
\hline Within Groups & 151 & 311.47 & 2.06 & & \\
\hline Total & 153 & 711.28 & 9.45 & & \\
\hline
\end{tabular}




\section{Discussion:}

This analytical cross-sectional study was carried out among 154 diabetes mellitus patients who attended the OPD of BIRDEM hospital, Dhaka, Bangladesh with a view to determine the disability burden posed by the disease and its complications. Burden of the disease was estimated in terms of years lived with disability (YLD) and compared in respect of sociodemographic characters of the patients, complications of the disease and patient's compliance with therapy. Total years lived with disability (YLD) due to DM and complications was estimated 473.43 (Mean $\mathrm{YLD}=3.07 \pm 2.16)$ in this particular study. It was reflected that more YLD was incurred by the patients within productive period of life (40-49 years) and by the higher income group of patients. By education, YLD was more in both illiterate and highly educated groups. 'DM with multiple complications' incurred more mean YLD (7.36 \pm 2.15$)$ followed by $3.81 \pm 1.66$ and $0.75 \pm 0.23$ mean $\mathrm{YLD}$ was Shared by 'DM with single complication' and 'only DM', which was statistically significant $(\mathrm{F}=96.92, \mathrm{p}<0.01)$. Though difference of YLD between 'only DM' \&'DM with single complication' and 'between 'only DM' \& 'DM with multiple complications' was statistically significant but the difference of YLD between 'DM with single complication' and 'DM with multiple complication' was not statistically significant $(\mathrm{p}>0.05)$.

According to therapy, out of 154 patients, 18 patients (11.7\%) were on diet control and daily walking (without medicine), 78 patients $(50.6 \%)$ were on oral hypoglycemic agent (OHA), 44 patients $(28.6 \%)$ were on insulin and 14 patients $(9.09 \%)$ were on both insulin and OHA therapy. These findings were consistent with the findings of the study conducted by AM Sarker et al in $1996 .{ }^{19}$ On the basis compliance with therapy, patients were categorized into 3 categories; patients with 'Good compliance with therapy' who comprised $29(18.83 \%)$ patients, 'Moderate compliance with therapy' who comprised $51(33.12 \%)$ and 'Poor compliance with therapy' who comprised 74 (48.05\%) patients. It was revealed that patients with 'poor compliance with therapy' incurred more YLD (52.65\%) than patients with 'moderate compliance with therapy' (34.27\%) and the patients with 'good compliance with therapy' (13.08\%), which was statistically significant $(\mathrm{F}=27.92, \mathrm{p}<0.01)$.

The mean duration of the disease was lower (4.88 years) among uncomplicated patients than of complicated diabetes patients (8.32 years), which was statistically significant (' $\mathrm{t}$ ' $\left.{ }_{(152)}=3.86,{ }_{\mathrm{P}}<0.01\right)$. It was also seen that disease duration was more among patients with 'multiple complications' $(10.83 \pm 5.91$ years) than 'Only DM' (4.86 \pm 3.12 years) and 'DM with single complication' ( $8.21 \pm 5.40$ years) and this discrepancy was statistically significant $(F=8.69$, $\mathrm{p}<0.01$ ). Disease duration was strongly correlated with YLD with statistical significance (' $\mathrm{t}$ ' ${ }_{(152)}=8.71, \mathrm{p}<0.01$ because complications were more among the patients with long duration. It was also found that age of the patients was strongly correlated with YLD with statistical significance (' $\mathrm{t}$ ' ${ }_{(152)}=9.53, \mathrm{p}<0.01$ ) because with increase in age there was increase in YLD. It was reflected that with increase in age of the patient, there was increase in duration and complications of the disease and as a result more YLD was incurred. These associations were consistent with the findings of the Global Disease Burden study. ${ }^{16,17}$

\section{Conclusion:}

The study was conducted among DM patients who attended the OPD of BIRDEM hospital to estimate disability burden of DM and its complications. It was found that more disability burden (YLD) was incurred by complications of DM, which was more among female patients. Nephropathy, cardiovascular disease, retinopathy \& neuropathy were the predominant complications. More YLD was directly associated with increase of age and long duration of disease but it was more among middle economic class. Both illiterate and educated patients shared higher YLD. Poor patient compliance with therapy incurred more YLD. To reduce disability burden of $\mathrm{DM}$, its perilous complications should be averted by early diagnosis \& prompt treatment along with adherence to therapy.

\section{Acknowledgement}

Department of Community Medicine, NIPSOM, Dhaka

\section{References:}

1. The World Health Report. The double burden: emerging epidemics and persistent problem. World Health Organization, Geneva, 1999: 13-16.

2. World Health Organization (WHO). Definition, Diagnosis and Classification of Diabetes Mellitus and its Complications. WHO, Geneva, 1999; 2: $2-12$.

3. South East Asia Regional Office (SEARO) World Health Organization (WHO), Non-communicable diseases prevention and management. SEAR, WHO 2002: 1-14. 
4. Jervell J. An Update on diabetes including HbA1C and Micro albumin. First Edition. Axis-Shield PoCAS, Oslo, Norway 2000: 6-37.

5. King H, Aubert RE, Herman WH. Global burden of diabetes 1995-2025. Prevalence, numerical estimates and projections. Diabetes care 1998; 21: 1414-1431.

6. Mahbub H, Ibrahim M, Banik NG, Jahan GE, Haque F, Ali SMK. Diabetes detection survey in a rural and semi-urban community in Bangladesh. Tohoku J. exp. Med. 1983; 141: 211-217.

7. Sayeed MA, Hussain MZ, Banu A, Rumi MAK and Khan AKA. Prevalence of diabetes in a suburban population of Bangladesh. Diabetes Research and Clinical Practice 1997; 34: 149-155.

8. Sayeed MA, Ali L, Hussain MZ, Rumi MAK, Banu A and Khan AKA. Effect of socioeconomic risk factors on the difference in prevalence of diabetes between rural and urban populations in Bangladesh. Diabetes Care 1997; 20: 551-555.

9. Sayeed MA, Khan AR, Banu A, Hossain MZ. Prevalence of diabetes and hypertension in a rural population of Bangladesh. Diabetes care 1995; 18(4): $555-558$

10. Sayeed MA, Mahtab H, Khanam PA, Latif ZA, Ali SMK, Banu A et al. Diabetes and Impaired Fasting Glycemia in a rural population of Bangladesh. Diabetes Cae 2003; 26: 1034-1039.

11. Khan AKA, Mahtab $\mathrm{H}$ and Islam MA. Characteristics of Diabetics Registered at BIRDEM. Scientific Report Series No.1. Epidemiology \& Statistics department, BIRDEM, 1979: 21-32.

12. Khan AKA, Mahtab H, Latif ZA, Hussain MZ. Characteristics of diabetics registered at BIRDEM 1981. J Diab Asso Bang 1992; 2: 32-43.
13. Record book for patient's registration of Bangladesh Institute of Research and Rehabilitation in Diabetes, Endocrine and Metabolic Disorders (BIRDEM), April 2003.

14. Statistics from Diabetic Association of Bangladesh (DAB). Source: http://www.diabetes-bd.org/diabetes in Bangladesh.htr. Accessed on April 2003.

15. Homedes N. The disability adjusted life year (DALY): Definition, measurement and potential use. HCO working paper 2000: 1-5.

16. Murray CJL, Lopez AD. Final results and their sensitivity to alternative epidemiological perspective: Discount rate, Age weight and Disability weight. In: Murray CJL, Lopez AD, editors. The global burden of disease: a comprehensive assessment of mortality and disability from diseases, injures and risk factors in 1990 and projected to 2020. Cambridge, Harvard University Press 1996: 250-287.

17. Murray CJL, Lopez AD. Global and Regional Descriptive Epidemiology of Disability: Incidence, Prevalence, Health expectancies and Years Lived with Disability. In: Murray CJL, Lopez AD. The Global burden of disease: a comprehensive assessment of mortality \& disability from diseases, injuries and risk factors in 1990 and Projected to 2020. Cambridge, Harvard University Press: 1996: 231-237.

18. Ascencio L, Mora F, Block G. Burden of disease in the aged, Mexico, 1994. Salud-publica-Mex. 1996; 38(6): 419-429.

19. Sarker AM, Miah MAB, Pathan MF, Khan AKA, Latif ZA. Treatment patterns in type 2 diabetes patients - impacts on glycemic control. DiabEndorl J 2001; 29(1): 15-18. 